\title{
Congruent Mammalian Trees from Mitochondrial and Nuclear Genes Using Bayesian Methods
}

\author{
Aurelio Reyes, ${ }^{*}$ Carmela Gissi,$\uparrow$ Francois Catzeflis, $\uparrow$ Eviatar Nevo,§ Graziano Pesole,$\uparrow$ \\ and Cecilia Sacconell
}

*Sezione di Bioinformatica e Genomica, Istituto Tecnologie Biomediche C.N.R. Bari, Italy; $†$ Dipartimento di Scienze Biomolecolari e Biotecnologie. Università di Milano, Milano, Italy; †Laboratoire Paleontologie, Universite Sciences and Techniques, Montpellier, France; §University of Haifa, Haifa, Israel; and IIDipartimento di Biochimica e Biologia Molecolare, Università di Bari, Bari, Italy

\begin{abstract}
Analyses of mitochondrial and nuclear gene sequences have often produced different mammalian tree topologies, undermining confidence in the merit of molecular approaches with respect to "traditional" morphological classification. The recent sequencing of the complete mitochondrial genomes of two additional rodents (Spalax judaei and Jaculus jaculus) and one lagomorph (Ochotona princeps) has prompted us to reinvestigate the issue. Using Bayesian phylogenetics, we found phylogenetic relationships between mammalian species highly congruent with previous results based on nuclear genes. Our results show the existence of four primary lineages of placental mammals: Xenarthra, Afrotheria, Laurasiatheria, and Euarchontoglires. Relationships between and within these lineages strongly suggest that the gene trees may also be congruent with the underlying species phylogeny.
\end{abstract}

\section{Introduction}

Mammalian phylogenetics at the ordinal level remains one of the outstanding problems in systematics because of the lack of congruence between different data sets. Anatomical and paleontological data produce a moderately well-resolved tree for the 18 orders of living placental mammals. Four supraordinal associations have been described: (1) the grouping Xenarthra and Pholidota at the base of the tree; (2) Archonta, comprising Primates, Scandentia, Chiroptera, and Dermoptera; (3) Glires, joining Rodentia and Lagomorpha; and (4) Ferungulata, which includes Carnivora, Tubulidentata, Perissodactyla, Artiodactyla, Proboscidea, Hyracoidea, and Sirenia (Novacek 1992; Shoshani and McKenna 1998). Molecular sequence data not only produce a completely different view of the supraordinal grouping of placental mammals but also show different results when nuclear or mitochondrial sequences are under consideration. Recent surveys based on nuclear genes (Madsen et al. 2001; Murphy et al. 2001a; Murphy et al. 2001b) have identified four primary supraordinal clades: Afrotheria, Xenarthra, Euarchontoglires, and Laurasiatheria, the latter two forming the Boreoeutheria clade. Glires is placed as a sister taxon to Scandentia, Dermoptera, and Primates (Euarchonta). Laurasiatheria includes Carnivora, Pholidota, Perissodactyla, Cetartiodactyla, Chiroptera, and the insectivores Eulipotyphla. Afrotheria is generally placed at the base of the tree (Scally et al. 2001; Delsuc et al. 2002) and comprises the orders Sirenia, Hyracoidea, Proboscidea, Macroscelidea, Tubulidentata, and endemic African insectivores (Afrosoricidae), making the order Insectivora polyphyletic. By contrast, mitochondrial sequence data produce a tree in which insectivores Eulipotyphla are basal in the placental tree. Rodentia is paraphyletic, with murid rodents in a different clade than nonmurid rodents, and it is not a sister group of

Key words: mtDNA, phylogeny, Glires, rodent monophyly.

E-mail: graziano.pesole@unimi.it.

Mol. Biol. Evol. 21(2):397-403. 2004

DOI: $10.1093 / \mathrm{molbev} / \mathrm{msh} 033$

Advance Access publication December 5, 2003

Molecular Biology and Evolution vol. 21 no. 2

(C) Society for Molecular Biology and Evolution 2004; all rights reserved.
Lagomorpha. Afrotheria, clustering with Xenarthra, is not at the base of the tree, but a sister group of Laurasiatheria (Arnason et al. 2002; Reyes et al. 2000; Reyes, Pesole, and Saccone 2000).

Genes from the nuclear (Murphy et al. 2001b) and mitochondrial genomes (Arnason and Janke 2002) may produce distinct phylogenies as a result of different inheritance pathways, divergent selection pressures, and differential responses to processes such as lineage sorting, gene duplication/deletion, and hybrid speciation. Conversely, congruent phylogenies among these two genomes could strongly suggest that the gene trees are also congruent with the single underlying phylogeny, the species phylogeny. Therefore, comparison of gene phylogenies of the two genomes will provide an opportunity for robust reconstruction of the complex mammalian phylogeny.

In the light of this background, we have sequenced the complete mitochondrial genome of two rodent species, the blind mole rat (Spalax judaei) (Nevo, Ivanitskaya, and Beiles 2001) and the lesser Egyptian jerboa (Jaculus jaculus), along with a new lagomorph species, the American pika (Ochotona princeps).

\section{Materials and Methods}

Enriched mtDNA was isolated from frozen livers of blind mole rat (Spalax judaei) and lesser Egyptian jerboa (Jaculus jaculus) and from frozen heart and liver of American pika (Ochotona princeps), according to previously described methods for mammalian species (Arnason, Gullberg, and Widegren 1991). For the two rodent species, restriction fragments were generated by single or double digestions with BamHI, EcoRI, HindIII, and XbaI. The pika mtDNA was digested separately with BlnI and Spe I restriction enzymes and in a combined digestion with $\mathrm{XbaI}$ and HindIII. The restriction fragments were ligated into M13mp18/19 and cloned in Escherichia coli XL1Blue. Single stranded DNA of mitochondrial clones were sequenced using Thermo Sequenase Cy 5.5 Dye Terminator Cycle Sequencing Kit on a Seq $4 \times 4$ automated sequencer (Amersham Pharmacia Biotech). Both universal and numerous specific oligonucleotide primers, according 
Table 1

Complete Mammalian Mitochondrial Genomes Analyzed in This Study

\begin{tabular}{|c|c|c|c|}
\hline Taxon & Species & Common Name & Accession Number \\
\hline Primates & $\begin{array}{l}\text { Gorilla gorilla } \\
\text { Homo sapiens } \\
\text { Pan paniscus } \\
\text { Pongo pygmaeus } \\
\text { Hylobates lar } \\
\text { Lemur catta } \\
\text { Tarsius bancanus } \\
\text { Cebus albifrons } \\
\text { Macaca sylvanus } \\
\text { Papio hamadryas } \\
\text { Nycticebus coucang }\end{array}$ & $\begin{array}{l}\text { Gorilla } \\
\text { Human } \\
\text { Pygmy chimpanzee } \\
\text { Orangutan } \\
\text { Gibbon } \\
\text { Lemur } \\
\text { Tarsier } \\
\text { Capuchin } \\
\text { Barbary ape } \\
\text { Baboon } \\
\text { Slow loris }\end{array}$ & $\begin{array}{l}\text { D38114 } \\
\text { V00662 } \\
\text { D38116 } \\
\text { D38115 } \\
\text { X99256 } \\
\text { AJ421451 } \\
\text { AF348159 } \\
\text { AJ309866 } \\
\text { AJ309865 } \\
\text { Y18001 } \\
\text { AJ309867 }\end{array}$ \\
\hline Dermoptera & $\begin{array}{l}\text { Cynocephalus variegatus } \\
\text { Cynocephalus variegatus }\end{array}$ & $\begin{array}{l}\text { Flying lemur (1) } \\
\text { Flying lemur (2) }\end{array}$ & $\begin{array}{l}\text { AF460846 } \\
\text { AJ428849 }\end{array}$ \\
\hline Artiodactyla & $\begin{array}{l}\text { Bos taurus } \\
\text { Muntiacus muntjak } \\
\text { Ovis aries } \\
\text { Sus scrofa } \\
\text { Hippopotamus amphibius } \\
\text { Lama pacos }\end{array}$ & $\begin{array}{l}\text { Cow } \\
\text { Muntjac } \\
\text { Sheep } \\
\text { Pig } \\
\text { Hippopotamus } \\
\text { Alpaca }\end{array}$ & $\begin{array}{l}\text { V00654 } \\
\text { AY225986 } \\
\text { AF010406 } \\
\text { AJ002189 } \\
\text { AJ010957 } \\
\text { Y19184 }\end{array}$ \\
\hline Cetacea & $\begin{array}{l}\text { Balaenoptera physalus } \\
\text { Physeter catodon }\end{array}$ & $\begin{array}{l}\text { Fin whale } \\
\text { Sperm whale }\end{array}$ & $\begin{array}{l}\text { X61145 } \\
\text { AJ277029 }\end{array}$ \\
\hline Carnivora & $\begin{array}{l}\text { Arctocephalus forsteri } \\
\text { Canis familiaris } \\
\text { Eumetopias jubatus } \\
\text { Felis catus } \\
\text { Halichoerus grypus } \\
\text { Odobenus rosmarus } \\
\text { Phoca vitulina } \\
\text { Ursus americanus }\end{array}$ & $\begin{array}{l}\text { New Zealand fur seal } \\
\text { Dog } \\
\text { Steller sea lion } \\
\text { Cat } \\
\text { Gray seal } \\
\text { Atlantic walrus } \\
\text { Harbor seal } \\
\text { Black bear }\end{array}$ & $\begin{array}{l}\text { AF513820 } \\
\text { U96639 } \\
\text { AJ428578 } \\
\text { U20753 } \\
\text { X72004 } \\
\text { AJ428576 } \\
\text { X63726 } \\
\text { AF303109 }\end{array}$ \\
\hline Perissodactyla & $\begin{array}{l}\text { Equus caballus } \\
\text { Rhinoceros unicornis } \\
\text { Ceratotherium simum }\end{array}$ & $\begin{array}{l}\text { Horse } \\
\text { Indian rhinoceros } \\
\text { White rhinoceros }\end{array}$ & $\begin{array}{l}X 79547 \\
X 97336 \\
Y 07726\end{array}$ \\
\hline Macroscelidae & Macroscelides proboscideus & Elephant shrew & AJ421452 \\
\hline Pholidota & Manis tetradactyla & Pangolin & AJ421454 \\
\hline Proboscidea & Loxodonta africana & African elephant & AJ224821 \\
\hline Sirenia & Dugong dugon & Dugong & AY075116 \\
\hline Tubulidentata & Orycteropus afer & Aardvark & Y18475 \\
\hline Scandentia & Tupaia belangeri & Tree shrew & AF217811 \\
\hline Xenarthra & $\begin{array}{l}\text { Dasypus novemcinctus } \\
\text { Tamandua tetradactyla }\end{array}$ & $\begin{array}{l}\text { Armadillo } \\
\text { Southern tamandua }\end{array}$ & $\begin{array}{l}\text { Y11832 } \\
\text { AJ421450 }\end{array}$ \\
\hline $\begin{array}{l}\text { Rodentia } \\
\text { Muridae } \\
\text { Muridae } \\
\text { Muridae } \\
\text { Spalacidae } \\
\text { Sciuridae } \\
\text { Gliridae } \\
\text { Dipodidae } \\
\text { Phiomorpha } \\
\text { Caviomorpha } \\
\text { Lagomorpha }\end{array}$ & $\begin{array}{l}\text { Volemys kikuchii } \\
\text { Mus musculus } \\
\text { Rattus norvegicus } \\
\text { Spalax judaei } \\
\text { Sciurus vulgaris } \\
\text { Glis glis } \\
\text { Jaculus jaculus } \\
\text { Thryonomys swinderianus } \\
\text { Cavia porcellus } \\
\text { Lepus europaeus } \\
\text { Oryctolagus cuniculus } \\
\text { Ochotona princeps }\end{array}$ & $\begin{array}{l}\text { Taiwan vole } \\
\text { Mouse } \\
\text { Rat } \\
\text { Blind mole rat } \\
\text { Squirrel } \\
\text { Fat dormouse } \\
\text { Lesser Egyptian jerboa } \\
\text { Cane rat } \\
\text { Guinea pig } \\
\text { European hare } \\
\text { Rabbit } \\
\text { American pika }\end{array}$ & $\begin{array}{l}\text { AF348082 } \\
\text { V00711 } \\
\text { X14848 } \\
\text { AJ416891 } \\
\text { AJ238588 } \\
\text { AJ001562 } \\
\text { AJ416890 } \\
\text { AJ301644 } \\
\text { AJ222767 } \\
\text { AJ421471 } \\
\text { AJ001588 } \\
\text { AJ537415 }\end{array}$ \\
\hline $\begin{array}{l}\text { Insectivora } \\
\text { Erinaceidae } \\
\text { Erinaceidae } \\
\text { Soricidae } \\
\text { Soricidae } \\
\text { Talpidae } \\
\text { Tenrecidae }\end{array}$ & $\begin{array}{l}\text { Erinaceus europaeus } \\
\text { Echinosorex gymnura } \\
\text { Soriculus fumidus } \\
\text { Sorex unguiculatus } \\
\text { Talpa europaea } \\
\text { Echinops telfairi }\end{array}$ & $\begin{array}{l}\text { European hedgehog } \\
\text { Moon rat } \\
\text { Asian shrew } \\
\text { Long-clawed shrew } \\
\text { European mole } \\
\text { Madagascar hedgehog }\end{array}$ & $\begin{array}{l}\text { X88898 } \\
\text { AF348079 } \\
\text { AF348081 } \\
\text { AB061527 } \\
\text { Y19192 } \\
\text { AJ400734 }\end{array}$ \\
\hline
\end{tabular}


Table 1

Continued

\begin{tabular}{lll}
\hline Taxon & \multicolumn{1}{c}{ Species } & Common Name \\
\hline Marsupialia & Macropus robustus & Accession Number \\
& Trichosurus vulpecula & Wallaroo \\
& Didelphis virginiana & Brushtail possum \\
& Isoodon macrourus & Opossum \\
& Vombatus ursinus & Bandicoot \\
Monotremata & Ornithorhyncus anatinus & Common wombat \\
& Tachyglossus aculeatus & Platypus \\
\hline
\end{tabular}

a This study.

to the primer walking method, were used to complete the sequence of each fragment. The whole mt genome of the two rodents was cloned and then sequenced. The D-loop region and two additional short regions of the pika mtDNA were amplified using species-specific primer and the fragments directly sequenced. The sequencing of the pika Dloop was not completed because of the presence of repeat sequences.

A total of 70 mammalian species, covering 17 orders of placental mammals, plus Marsupialia and Monotremata as outgroups, were analyzed (table 1 ). When more mtDNA sequences were available for the same genus, only one species for genus was selected. However, the two available Cynocephalus mtDNA sequences were both included in the analyses data set, because of their remarkable differences at sequence level. The ungapped first and second codon positions of mitochondrial H-stranded proteincoding genes, with the exclusion of leucine synonymous sites in first codon position (Leu-SynP1), were retained for phylogenetic analysis (6,025 nucleotides).

Phylogenetic analysis was carried out by the MrBayes program (Larget and Simon 1999; Huelsenbeck et al. 2001) using the General-Time-Reversible (GTR) substitution model (Saccone et al. 1990) for nucleotide sequences and "mtmam" model for protein sequences, with the invariant site plus gamma options (five categories). One cold and three incrementally heated chains were run for 2,000,000 generations with chains $i=2,3$, and 4 incrementally heated with heat being $1 /(1+[i-1] T)$ and $T=0.2$. Trees were sampled every 100 generations from the last 1,000,000 generated (well after the chain reached stationarity) and 10,000 trees were used for inferring bayesian posterior probability.

Maximum-likelihood analysis was carried out using PAUP* using GTR $+\Gamma+\mathrm{I}$ model with given model parameters estimated on a neighbor-joining tree. Alternative tree topologies were investigated using the approximately unbiased test, as implemented in the program CONSEL (Shimodaira and Hasegawa 2001).

\section{Results and Discussion}

Phylogenetic analysis has been carried out on the multialignment, including ungapped first and second codon positions of mitochondrial $\mathrm{H}$-stranded proteincoding genes, with the exclusion of leucine synonymous sites in first codon positions (Leu-SynP1). Leucine is the most abundant amino acid in the aligned mitochondrial proteins $(16.3 \% \pm 0.5)$ and the Leu codon usage is quite different between species (Leu-CTN 13.0\% \pm 1.4; LeuTTR $3.2 \% \pm 1.2$ ) (see table 2 ). In the amino acid alignment, $32.6 \%$ of ungapped sites contain two or more Leu, with $85.7 \%$ of such Leu sites showing synonymous substitutions in first codon position. All the Leu invariant sites present synonymous substitutions in the first codon position (table 3). Moreover, the data set containing Leu sites (7,040 nucleotides) show a statistically significant compositional heterogeneity (chi-square test, $P<0.00001$ ), mostly because of the deviation of Erinaceomorpha sequences from the mean base frequency (relative chisquare contribution of $11.6 \%$ and $7.9 \%$ for Erinaceus and Echinosorex, respectively). On the contrary, the exclusion of Leu-SynP1 eliminates most of the compositional bias (chi-square test, $P=0.97$ ) and makes the Erinaceomorpha sequences almost compositionally homogeneous. In conclusion, the Leu-SynP1 sites need to be excluded from the phylogenetic data set to avoid compositional bias and substitution saturation effects.

We applied a Bayesian method for phylogenetic reconstruction being maximum-likelihood impracticableunless with given substitution parameters and/or tree constraints - for the large data set considered here. Indeed, Bayesian analysis shows considerable promise because it allows simultaneous estimation of the uncertainty associated with any parameter from the phylogenetic model (topology, branch lengths, and substitution models) through the use of the posterior probability distribution. Because phylogenetic reconstruction is a complex estimation problem, Markov Chain Monte Carlo (MCMC) methods are needed to estimate the posterior distribution of these parameters. Bayesian methods have been successfully applied to the estimation of the tree topology of placentals by using nuclear data (Murphy et al. 2001a).

Figure 1 shows a phylogenetic tree with Bayesian posterior probabilities for individual branches. The phylogeny of placental mammals is well resolved and, with the exception of eight nodes, posterior probabilities are higher than 0.85 . The results affirm the monophyly of traditional placental orders (except for Primates, Artiodactyla, and Insectivora) and support the supraordinal clades of Afrotheria, Laurasiatheria, and Euarchontoglires, previously proposed based on nuclear gene analyses (Madsen et al. 2001; Murphy et al. 2001a; Murphy et al. $2001 b$ ). Apart some minor topological differences (within Cetartiodactyla and Eulipotyphla), the phylogenetic recontruction presented here is substantially congruent with 
Table 2

Frequency Percentage of Leucine Codons Calculated on the Ungapped Sites of the Aligned $12 \mathrm{H}$-Strand Protein-Coding Genes for the Species Listed in Table 1

\begin{tabular}{lllllllr}
\hline & CTA & CTG & CTC & CTT & TTA & TTG & Total \\
\hline Mean & 7.22 & 0.92 & 2.65 & 2.23 & 2.97 & 0.30 & 16.28 \\
SD & 0.98 & 0.44 & 0.97 & 0.63 & 1.17 & 0.15 & 0.50 \\
Minimum & 4.8 & 0.23 & 0.6 & 1.31 & 1.45 & 0.03 & 15.34 \\
Maximum & 9.46 & 2.05 & 4.91 & 3.92 & 6.68 & 0.71 & 17.7 \\
\hline
\end{tabular}

that previously obtained with nuclear genes. A general agreement between mitochondrial and nuclear trees has been previously observed during analyses of mitochondrial rRNA (Jow et al. 2002) and protein genes but only with unrooted trees (Lin et al. 2002; Lin, Waddell, and Penny 2002). Indeed, the mitochondrial placental tree was different from the nuclear one when marsupial and/or monotreme outgroups were used (Lin et al. 2002; Lin, Waddell, and Penny 2002).

A tree topology similar to that of figure 1 has been obtained from carrying out the Bayesian analysis on all ungapped first and second codon positions, including Leu-SynP1, and on protein data, except for the basal region of the tree (data not shown) where Erinaceomorpha becomes basal with respect to all other placentals, and a new clade of Xenarthra plus Afrotheria appears as sister group of Euarchontoglires (data not shown). However, we assessed the confidence level of different rootings of the placental trees by using the approximately unbiased (AU) test, as implemented in the program CONSEL (Shimodaira and Hasegawa 2001). A basal placement of Xenarthra (Epitheria hypothesis) or a basal Afrotheria + Xenarthra group was a not-significantly-worse explanation of the data than was a basal Afrotheria, the $P$-values of the AU test being 0.198 and 0.384 , respectively. This is probably a result of the poor taxon sampling of Xenarthra (Delsuc et al. 2002), whose position in the placental tree is rather unstable and variable as it changes according to whether protein or nucleotide sequences are used and according to the taxon sampling. Figure 1 shows two supraordinal clades of Eutheria, Laurasiatheria, and Euarchontoglires, with Xenarthra apparently more strictly related to the latter.

Within Euarchontoglires, our results support the position of Scandentia as outgroup and Dermoptera as sister group of the Anthropoidea, which makes Primates polyphyletic in agreement with previous results obtained on mitochondrial data (Arnason et al. 2002). Nuclear data have not resolved this issue (Murphy et al. 2001a) and does not support the monophyly of Primates and a sister relationship between Dermoptera and Scandentia using a limited taxon sampling (Murphy et al. 2001b). The polyphyletic Primates are highly supported $(\mathrm{PP}=100)$ by both nucleotide and protein trees. Indeed, Primates monophyly was significantly rejected for (Primates [Dermoptera, Scandentia]) and (Dermoptera [Primates, Scandentia]) topologies $(P<0.05$ in AU test). Only a (Scandentia [Primates, Dermoptera]) topology could not be significantly rejected by the AU test $(P=0.056)$.

Within Laurasiatheria, the only striking difference with molecular phylogenies based on nuclear data is the
Table 3

Number of Sites of the Analyzed Ungapped Amino Acid Alignment Showing Leucine Residues

\begin{tabular}{lr}
\hline Sites & Number \\
\hline At least 1 Leu & 1,340 \\
Only 1 Leu & 191 \\
$\geq 2$ Leu & 1,149 \\
Leu-SynP1 & 985 \\
Invariant Leu (all Leu-SynP1) & 167 \\
Total alignment & 3,520 \\
\hline
\end{tabular}

NotE.-Leu-SynP1: synonymous substitutions on first codon position of Leu sites.

different positions of alpaca and pig. Pig emerges basal to other Cetartiodactyla in both nucleotide (fig. 1) and protein tree (not shown), whereas the alpaca is more closely related to the clade that includes hippo and Cetacea in the nucleotide tree (fig. 1) and basal with respect to other Cetartiodactyla (excluding pig) in the protein tree (not shown). However, the nuclear topology with a basal alpaca cannot be rejected by the AU test $(P=0.103)$.

One of the most debated issues among morphologists, paleontologists, and molecular biologists is the position of Rodentia within the mammalian tree and the relationship among the major lineages of Rodentia. The monophyly of Rodentia and Glires as well as the position of the latter as a sister group of Primates is significantly supported for the first time by mitochondrial genes (fig. 1) in both the nucleotide $(\mathrm{PP}=100$ [see fig. 1]) and the protein tree $(\mathrm{PP}=$ 86 [data not shown]). The observed rodent monophyly and the support for the Glires clade is in clear contrast with previous mitochondrial surveys, which showed rodent paraphyly (Reyes, Pesole, and Saccone 1998; Reyes et al. 2000; Reyes, Pesole, and Saccone 2000; Arnason et al. 2002 [but see Philippe 1997; Sullivan and Swofford 1997]). This is most likely caused by the inclusion of new rodent mitochondrial genomes that would break the long branches leading to Muridae (Reyes, Pesole, and Saccone 2000) rather than to the exclusion of leucine synonymous sites from the data set and the use of the Bayesian phylogenetic method. Indeed, rodent monophyly is maintained if leucine synonymous sites are included or the phylogenetic tree is reconstructed using the maximum-likelihood method (data not shown). Such results (fig. 1) are in perfect agreement with those obtained from nuclear gene trees (Madsen et al. 2001; Murphy et al. 2001a; Murphy et al. $2001 b$ ) and with morphological and paleontological data (Carroll 1988; Luckett and Hartenberger 1993).

Regarding the relationships among rodent families, our data support the clustering of Gliridae with Sciuridae and a Caviomorpha plus Phiomorpha clade. Muridae, Spalacidae, and Dipodidae are placed in a different clade (fig. 1). The separation of rodents into these clades is in agreement with previous results based on complete mitochondrial genomes (Reyes, Pesole, and Saccone 1998; Reyes et al. 2000; Reyes, Pesole, and Saccone 2000; Arnason et al. 2002). Nuclear genes show either a polytomy for the major lineages of rodents or Muridae clustering with Caviomorpha and Phiomorpha, leaving Sciuridae and Gliridae as the most divergent groups (Madsen et al. 2001; Murphy et al. 2001a; Murphy et al. 2001b; Huchon 


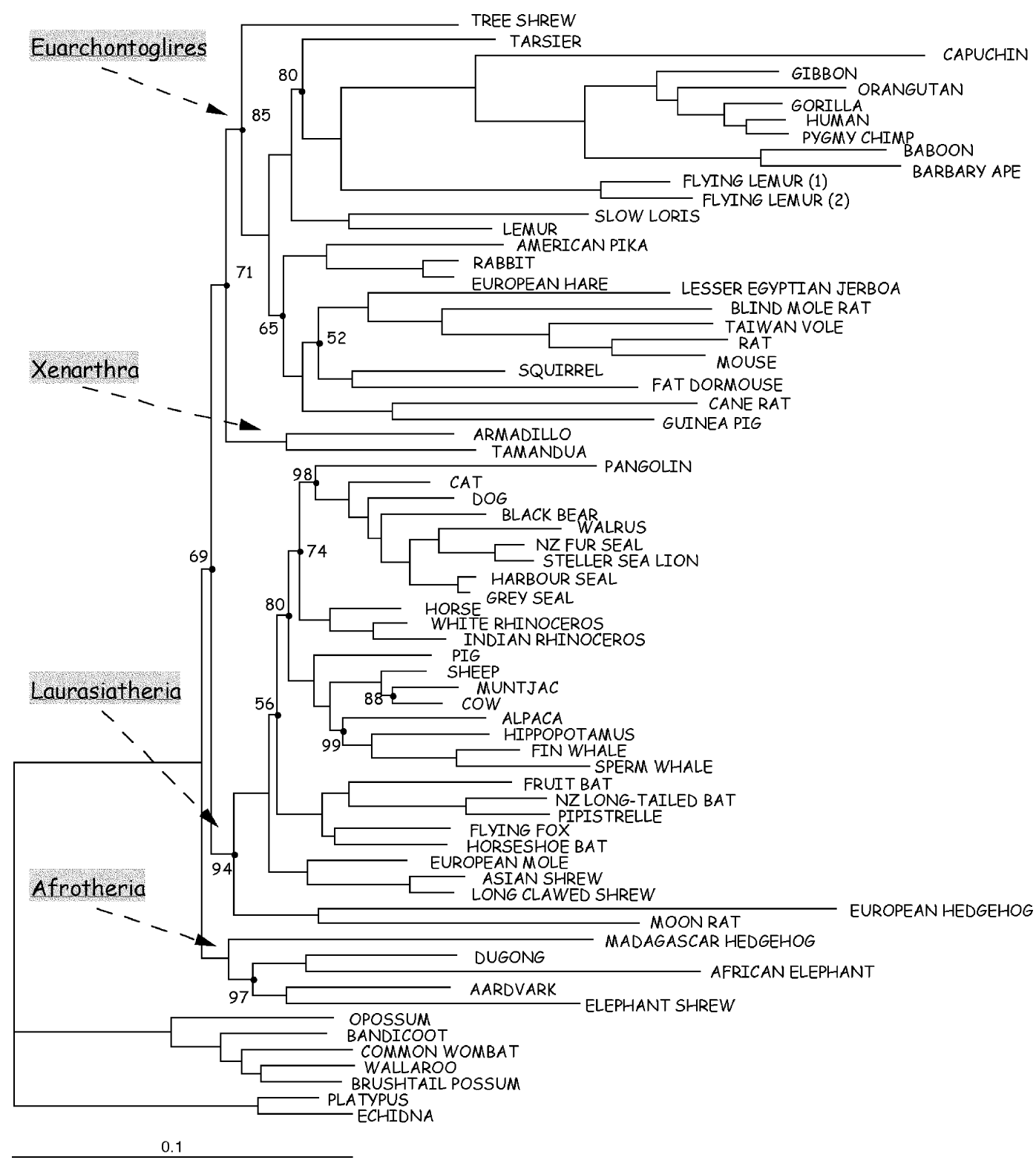

FIG. 1.-Phylogenetic tree of placental mammals reconstructed using the program MrBayes from mitochondrial H-stranded protein-coding genes using ungapped first and second codon positions with the exclusion of Leu synonymous sites. Posterior probabilities (PP) supporting the tree nodes are only reported when less than 100. Marsupialia and Monotremata were used as outgroups. The lengths of the branches are proportional to the number of nucleotide substitutions per site.

et al. 2002). Traditional morphological classifications also provide a different view of relationships among rodent families: Gliridae is the closest relative to the clade containing Dipodidae plus Spalacidae and Muridae, then Sciuridae, and finally Caviomorpha together with Phiomorpha (McKenna and Bell 1997). However, other morphological and paleontological surveys provide evidence for the close relationship between Gliridae and Sciuridae (Bugge 1985; Lavocat and Parent 1985; Hartenberger 1996), giving further support to our data. None of these alternative tree topologies based on nuclear, morphological, or paleontological data can be rejected by our data $(P>0.05$ in AU tests). This suggests that taxon sampling among the numerous families of rodents might not be extensive enough to discriminate between the best tree and the alternative topologies, thus highlighting the need for more comprehensive sampling.

The other controversial point is the position of lagomorphs within the mammalian tree and, in particular, their association with rodents in the cohort Glires. Our results highly support the clustering of Lagomorpha and Rodentia in Glires (fig. 1). Based on morphology, Glires has always been considered as a monophyletic group with well-defined characters (Hartenberger 1996; Archibald, Averianov, and Ekdale 2001), but this view has been frequently challenged by molecular studies, based on both nuclear and mitochondrial genes. In these studies, lagomorphs appeared as a clade branching off before the split between Primates and Ferungulata or as a sister clade of Euarchonta (Graur, Duret, and Gouy 1996; Reyes, 
Pesole, and Saccone 1998; Reyes et al. 2000; Reyes, Pesole, and Saccone 2000; Arnason et al. 2002). Both hypotheses were rejected by our data based on mitochondrial genomes ( $P<0.01$ in AU tests). Recent surveys based on complete mitochondrial genomes had suggested a close relationship between Lagomorpha and certain families of Rodentia (Reyes et al. 2000; Reyes, Pesole, and Saccone 2000), but it has been mainly by means of nuclear genes that the existence of Glires has been highly supported (Madsen et al. 2001; Murphy et al. 2001a; Murphy et al. 2001b; Huchon et al. 2002). Our study strongly supports the existence of Glires, probably as consequence of a more comprehensive sampling of both Lagomorpha and Rodentia.

The fourth superordinal lineage, Laurasiatheria, includes the remaining placental orders: Carnivora, Perissodactyla, Cetartiodactyla, Chiroptera, and core Insectivora (fig. 1). The clustering of these orders has received support from previous surveys based on both complete mitochondrial genomes (Reyes, Pesole, and Saccone 1998; Reyes et al. 2000; Reyes, Pesole, and Saccone 2000; Arnason et al. 2002) and nuclear genes (Madsen et al. 2001; Murphy et al. 2001a; Murphy et al. 2001b). The monophyly of Chiroptera, which has been a controversial issue over the last decade (Pettigrew 1986), is well supported by our data. The polyphyly of Eulipotyphla, with Soricomorpha and Erinaceomorpha forming a paraphyletic group, is also well supported by our data (fig. 1), but a misplacement because of the presence of some residual compositional bias in Erinaceomorpha cannot be excluded.

Bayesian phylogenetic reconstruction has provided remarkable resolving power, with only $12 \%$ of the nodes in the tree (8/68) showing PP $<0.85$. Although it is likely that Bayesian approach results in overcredibility of some nodes (Suzuki, Glazko, and Nei 2002; Alfaro, Zoller, and Lutzoni 2003; Douady et al. 2003) — and this also emerges from some AU tests presented here-we are confident of the general reliability of the obtained topology. This derives from the observation that ML reconstruction, under the GTR $+\Gamma+$ I model, carried out on the same data (not shown), was fully topologically congruent with Bayesian reconstruction. The utility of mitochondrial DNA for phylogenetic reconstruction is based on the fact that the mitochondrial genes are inherited as a single nonrecombining linkage unit and thus do not provide independent estimates of the species tree. In contrast, because nuclear genes are usually selected randomly from different chromosomes, each gene tree may provide an independent estimate of the species tree. In addition, the effective population size of mitochondrial genes is smaller than that of nuclear genes as a consequence of their different mode of inheritance. Because it is known that effective population size has a great impact in the accuracy of phylogenetic reconstruction, specially between successive bifurcations, mitochondrial genes tree have a better chance of tracking the species tree than nuclear gene (Moore 1995). In this sense, contrasting perspectives have been obtained in different surveys regarding the merits of nuclear and mitochondrial genes for recovering phylogenetic information. One of them states that mitochondrial genes would be more efficient in recovering resolved mammalian phylogenies and that only with a much higher number of nuclear genes similar results could be obtained (Arnason, Gullberg, and Janke 1999). By contrast, the other perspective claims that if sequence length is comparable, nuclear genes have a greater resolving power than mitochondrial genes (Springer et al. 2001). However, our study shows that mitochondrial and nuclear genes are equally reliable for recovering order-level and family-level relationships among eutherian mammals when comprehensive taxon sampling is used, compositional bias is taken into account, and robust methods are used for tree reconstruction.

\section{Acknowledgments}

This work was supported by Ministero dell'Istruzione, Università e Ricerca, Italy (FIRB, FIRST and Cluster C03/2000 projects) and "Progetto Giovani Ricercatori" of the University of Milano. We thank Dr. David J. Hafner of the New Mexico Museum of Natural History for the gift of Ochotona princeps frozen tissues, Alessandra Marinelli for help in pika mtDNA cloning, and David Horner for valuable comments on the manuscript.

\section{Literature Cited}

Alfaro, M. E., S. Zoller, and F. Lutzoni. 2003. Bayes or bootstrap? A simulation study comparing the performance of Bayesian Markov Chain Monte Carlo sampling and bootstrapping in assessing phylogenetic confidence. Mol. Biol. Evol. 20: 255-266.

Archibald, J. D., A. O. Averianov, and E. G. Ekdale. 2001. Late Cretaceous relatives of rabbits, rodents, and other extant eutherian mammals. Nature 414:62-65.

Arnason, U., J. A. Adegoke, K. Bodin, E. W. Born, Y. B. Esa, A. Gullberg, M. Nilsson, R. V. Short, X. Xu, and A. Janke. 2002. Mammalian mitogenomic relationships and the root of the eutherian tree. Proc. Natl. Acad. Sci. USA 99:81518156.

Arnason, U., A. Gullberg, and A. Janke. 1999. The mitochondrial DNA molecule of the aardvark, Orycteropus afer, and the position of the Tubulidentata in the eutherian tree. Proc. R. Soc. Lond. B Biol. Sci. 266:339-345.

Arnason, U., A. Gullberg, and B. Widegren. 1991. The complete nucleotide sequence of the mitochondrial DNA of fin whale, Balaenoptera physalus. J. Mol. Evol. 33:556-568.

Arnason, U., and A. Janke. 2002. Mitogenomic analyses of eutherian relationships. Cytogenet. Genome Res. 96:20-32.

Bugge, J. 1985. Systematic value of the carotid arterial pattern in rodents. Pp. 333-354 in W. P. Luckett and J.-L. Hartenberger, eds. Evolutionary relationships among rodents. A multidisciplinary analysis. Plenum Press, New York.

Carroll, R. L. 1988. Vertebrate paleontology and evolution. W.H. Freeman and Company, New York.

Delsuc, F., M. Scally, O. Madsen, M. J. Stanhope, W. W. de Jong, F. M. Catzeflis, M. S. Springer, and E. J. Douzery. 2002. Molecular phylogeny of living xenarthrans and the impact of character and taxon sampling on the placental tree rooting. Mol. Biol. Evol. 19:1656-1671.

Douady, C. J., F. Delsuc, Y. Boucher, W. F. Doolittle, and E. J. Douzery. 2003. Comparison of Bayesian and maximum likelihood bootstrap measures of phylogenetic reliability. Mol. Biol. Evol. 20:248-254. 
Graur, D., L. Duret, and M. Gouy. 1996. Phylogenetic position of the order Lagomorpha (rabbits, hares and allies). Nature 379:333-335.

Hartenberger, J.-L. 1996. Les débuts de la radiation adaptive des Rodentia (Mammalia). C.R. Acad. Sci. Paris 323:631-637.

Huchon, D., O. Madsen, M. J. Sibbald, K. Ament, M. J. Stanhope, F. Catzeflis, W. W. de Jong, and E. J. Douzery. 2002. Rodent phylogeny and a timescale for the evolution of Glires: evidence from an extensive taxon sampling using three nuclear genes. Mol. Biol. Evol. 19:1053-1065.

Huelsenbeck, J. P., F. Ronquist, R. Nielsen, and J. P. Bollback. 2001. Bayesian inference of phylogeny and its impact on evolutionary biology. Science 294:2310-2314.

Jow, H., C. Hudelot, M. Rattray, and P. G. Higgs. 2002. Bayesian phylogenetics using an RNA substitution model applied to early mammalian evolution. Mol. Biol. Evol. 19: 1591-1601.

Larget, B., and D. L. Simon. 1999. Markov Chain Monte Carlo algorithms for the Bayesian analysis of phylogenetic trees. Mol. Biol. Evol. 16:750-759.

Lavocat, R., and J.-P. Parent. 1985. Phylogenetic analysis of middle ear features in fossil and living rodents. Pp. 333-354 in W. P. Luckett and J.-L. Hartenberger, eds. Evolutionary relationships among rodents. A multidisciplinary analysis. Plenum Press, New York.

Lin, Y. H., P. A. McLenachan, A. R. Gore, M. J. Phillips, R. Ota, M. D. Hendy, and D. Penny. 2002. Four new mitochondrial genomes and the increased stability of evolutionary trees of mammals from improved taxon sampling. Mol. Biol. Evol. 19:2060-2070.

Lin, Y. H., P. J. Waddell, and D. Penny. 2002. Pika and vole mitochondrial genomes increase support for both rodent monophyly and Glires. Gene 294:119-129.

Luckett, W. P., and J.-L. Hartenberger. 1993. Monophyly or polyphyly of the order Rodentia: possible conflict between morphological and molecular interpretations. J. Mammal. Evol. 1:127-147.

Madsen, O., M. Scally, C. J. Douady, D. J. Kao, R. W. DeBry, R. Adkins, H. M. Amrine, M. J. Stanhope, W. W. de Jong, and M. S. Springer. 2001. Parallel adaptive radiations in two major clades of placental mammals. Nature 409:610-614.

McKenna, M. C., and S. K. Bell. 1997. Classification of mammals above the species level. Columbia University Press, New York.

Moore, W. S. 1995. Inferring phylogenies from mtDNA variation: mitochondrial-gene trees versus nuclear-gene trees. Evolution 49:718-726.

Murphy, W. J., E. Eizirik, W. E. Johnson, Y. P. Zhang, O. A. Ryder, and S. J. O'Brien. 2001a. Molecular phylogenetics and the origins of placental mammals. Nature 409:614-618.

Murphy, W. J., E. Eizirik, S. J. O'Brien et al. (11 co-authors). $2001 b$. Resolution of the early placental mammal radiation using Bayesian phylogenetics. Science 294:2348-2351.
Nevo, E., E. Ivanitskaya, and A. Beiles. 2001. Adaptative radiation of blind subterranean mole rats: naming and revising the four sibling species of the Spalax ehrenbergi superspecies in Israel: Spalax galili $(2 \mathrm{n}=52)$, S. golani $(2 \mathrm{n}=54), S$. carmeli $(2 \mathrm{n}=58)$ and $S$. judaei $(2 \mathrm{n}=60)$. Bachkhuys Publisher, Leiden, The Netherlands.

Novacek, N. J. 1992. Mammalian phylogeny: shaking the tree. Nature 379:333-335.

Pettigrew, J. D. 1986. Flying primates? Megabats have the advanced pathway from eye to midbrain. Science 231:1304-1306.

Philippe, H. 1997. Rodent monophyly: pitfalls of molecular phylogenies. J. Mol. Evol. 45:712-715.

Reyes, A., C. Gissi, G. Pesole, F. M. Catzeflis, and C. Saccone. 2000. Where do rodents fit? Evidence from the complete mitochondrial genome of Sciurus vulgaris. Mol. Biol. Evol. 17:979-83.

Reyes, A., G. Pesole, and C. Saccone. 1998. Complete mitochondrial DNA sequence of the fat dormouse, Glis glis: further evidence of rodent paraphyly. Mol. Biol. Evol. 15:499-505.

Reyes, A., G. Pesole, and C. Saccone. 2000. Long-branch attraction phenomenon and the impact of among-site rate variation on rodent phylogeny. Gene 259:177-187.

Saccone, C., C. Lanave, G. Pesole, and G. Preparata. 1990. Influence of base composition on quantitative estimates of gene evolution. Methods Enzymol. 183:570-583.

Scally, M., O. Madsen, C. J. Douady, W. W. de Jong, M. J. Stanhope, and M. S. Springer. 2001. Molecular evidence for the major clades of placental mammals. J. Mammal. Evol. 8:239-277.

Shimodaira, H., and M. Hasegawa. 2001. CONSEL: for assessing the confidence of phylogenetic tree selection. Bioinformatics 17:1246-1247.

Shoshani, J., and M. C. McKenna. 1998. Higher taxonomic relationships among extant mammals based on morphology, with selected comparisons of results from molecular data. Mol. Phylogenet. Evol. 9:572-584.

Springer, M. S., R. W. DeBry, C. Douady, H. M. Amrine, O. Madsen, W. W. de Jong, and M. J. Stanhope. 2001. Mitochondrial versus nuclear gene sequences in deep-level mammalian phylogeny reconstruction. Mol. Biol. Evol. 18: 132-143.

Sullivan, J., and D. L. Swofford. 1997. Are guinea pigs rodents? The importance of adequate models in molecular phylogenetics. J. Mammal. Evol. 4:77-86.

Suzuki, Y., G. V. Glazko, and M. Nei. 2002. Overcredibility of molecular phylogenies obtained by Bayesian. Proc. Natl. Acad. Sci. USA 99:16138-16143.

Manolo Gouy, Associate Editor

Accepted October 8, 2003 